\title{
O PAPEL DAS POLÍTICAS PÚBLICAS E O DESENVOLVIMENTO REGIONAL NO BRASIL: DO PARADIGMA MENTALISTA AO LINGUÍSTICO
}

\author{
THE ROLE OF PUBLIC POLICIES AND REGIONAL DEVELOPMENT IN BRAZIL: \\ THE MENTALIST PARADIGM LANGUAGE \\ EL PAPEL DE LAS POLÍTICAS PÚBLICAS Y DESARROLLO REGIONAL EN \\ BRASIL: EL PARADIGMA DE LA LINGÜÍSTICA MENTALISTA
}

\author{
Rosalvo Nobre Carneiro - Universidade do Estado do Rio Grande do Norte - Pau dos Ferros - \\ Rio Grande do Norte - Brasil \\ rosalvonobre@uern.br
}

\section{Resumo}

0 papel das políticas públicas no desenvolvimento regional é analisado neste artigo, tomando por base dois grandes paradigmas científicos: 0 da subjetividade, ou mentalista, e o da intersubjetividade, ou linguístico. Defende-se que as políticas públicas e 0 desenvolvimento regional brasileiro têm se dado historicamente com base no primeiro paradigma e, só bem recentemente, adotado o segundo em algum momento da implantação dessas políticas. As politicas públicas de cunho mentalista, a que chamamos aqui de instrumentais, são subdivididas em desenvolvimentistas e neoliberais, ao passo que as politicas públicas linguísticas são vistas como comunicativas, isto é, com base na ação orientada para o entendimento mútuo, livre de coação. Trata-se de um trabalho de cunho teórico-metodológico, baseado nas abordagens desenvolvidas pelo filósofo Jürgen Habermas. A inclusão da teoria da ação comunicativa às questões espaciais pode contribuir para pensar o desenvolvimento regional como um modo de subordinação da economia à sociedade.

Palavras-chave: políticas públicas, desenvolvimento regional, paradigma mentalista, paradigma linguista, comunicação.

\section{Abstract}

The role of public policies on regional development is parsed based on two major scientific paradigms of subjectivity or mentalism and of intersubjectivity or linguistic. Argues that public policies and the Brazilian regional development have historically if given based on the first paradigm, and recently adopted the second at some point these policies. The public policies of imprint Mentalist we call here of instrumentals are subdivided into developmental and neoliberal while public policies are seen as communicative language, based in act oriented towards mutual understanding free of coercion. It is theoretical-methodological imprint, based on the imaginary of the philosopher Jürgen Habermas. The inclusion of the theory of communicative action on spatial issues can contribute to regional development thinking from the subordination of the economy to society.

Key words: public policy, regional development, mentalist paradigm, paradigm linguist, communication.

\section{Resumen}

El papel de las políticas públicas de desarrollo regional se analiza en función de dos paradigmas científicos principales de subjetividad o mentalismo y de intersubjetividad o lingüística. Argumenta que las políticas públicas y el desarrollo regional brasileño han históricamente si basada en el paradigma de la primero y recientemente aprobada la segunda en algún punto estas políticas. Las políticas públicas de impronta mentalista que llamamos aquí de instrumentales se subdividen en desarrollo y neoliberal mientras que 
las políticas públicas son vistas como lenguaje comunicativo, es decir, de la acción orientada hacia la comprensión mutua libre de coerción. Es huella teórico metodológica, basado en el imaginario del filósofo Jürgen Habermas. La inclusión de la teoría de la acción comunicativa sobre cuestiones espaciales puede contribuir a la reflexión sobre el desarrollo regional de la subordinación de la economía a la sociedad.

Palabras clave: políticas públicas, desarrollo regional, paradigma mentalista, lingüista paradigma, la comunicación.

As políticas públicas e os paradigmas mentalista e linguista

Na filosofia linguística defendida por Habermas (2003), a razão instrumental é substituída pela razão comunicativa, a ação orientada para o êxito pela ação orientada para o entendimento mútuo, o mundo sistêmico e seus símbolos - o poder e o dinheiro - pelo mundo vivido e seus símbolos: a linguagem ou os atos de fala. Os atos de fala são expressões humanas como ordens, confissões, constatações, assim como todo tipo de proferimentos linguísticos que possam auxiliar, em uma situação de agir comunicativo, duas ou mais pessoas a chegarem a um entendimento sobre algo (Habermas, 1990).

Defende-se que as políticas públicas no Brasil têm se baseado, historicamente, na filosofia da consciência e, apenas bem recentemente, a filosofia linguística tem sido adotada em alguma etapa, especialmente na de elaboração, ocasião em que a sociedade vem sendo chamada a falar e a ouvir na busca de entendimentos sobre algo nos mundos objetivo, subjetivo e social, objetos dessas políticas.

Consta, por exemplo, do $\S 4^{\circ}$, da Lei n. 10.257, de 10 de julho de 2001, que regulamenta os artigos 182 e 183 da Constituição Federal e estabelece diretrizes gerais da política urbana, que, "no processo de elaboração do plano diretor e na fiscalização de sua implementação, os Poderes Legislativo e Executivo municipais garantirão: I - a promoção de audiências públicas e debates com a participação da população e de associações representativas dos vários segmentos da comunidade” (Brasil, 2001).

Pelo fato de se ampararem na razão instrumental e nas ações orientadas para fins, as políticas públicas voltadas para o desenvolvimento regional relegaram as questões de humanidade e de integração social, próprias do mundo vivido. Neste quadro, a integração funcional, típica dos sistemas político e do mercado, prevaleceu como matriz do desenvolvimento regional brasileiro.

A política regional desenvolvimentista, no que tange aos aspectos de articulação territorial, apesar de ter sido lograda, não foi capaz de as- 
cender a outro nível que não o do desenvolvimento do sistema de objetos ou do mundo objetivo, e chegar, assim, a um desenvolvimento também do mundo subjetivo e social.

Cabe destacar que o paradigma mentalista dessa política confundia público com privado, particularmente porque o Capital aparecia como seu pilar de sustentação. As políticas públicas comunicativas trazem uma visão diferente sobre o que é público ou privado, e, consequentemente, apresentam uma visão diferenciada sobre o desenvolvimento regional.

O público das políticas públicas comunicativas de desenvolvimento regional é reconhecido no momento em que um grupo de atores sociais, todos falantes e ouvintes, reunidos em torno desse tema comum dos mundos objetivo, social e subjetivo, e tendo como suporte seus mundos sistêmicos e vividos partilhados intersubjetivamente, orientam seus planos de ação na busca de um entendimento sobre as questões que os envolvem, sem que o consenso seja resultante de coações, mas tão somente de processos de argumentação, contra-argumentação, aprendizagem e convencimento.

Toda vez que o entendimento mútuo em uma negociação não é atingido e o consequente ponto de vista de um ator se impõe, rompe-se o fundamento público comunicativo das políticas públicas, pois nesse caso o consenso não ocorre livremente, isto é, ele se dá dependente de coações e, portanto, o público se impõr do ponto de vista mentalista, já que entra nas relações entre meios e fins e, logo, confunde-se com o privado.

Apoiar as ações em torno de um entendimento é assumir, de antemão, a perspectiva do outro, descentrar-se, ou seja, não agir de forma egoísta. A subjetividade dos planos de ação deve dar lugar, sempre, do ponto de vista das políticas públicas comunicativas, à intersubjetividade, em que os implicados na comunicação se dirigem em direção a um ponto de possibilidades no horizonte que apareça como o melhor para todos.

Não é a reunião de vários falantes e ouvintes em um dado lugar e em torno de um tema comum nos mundos objetivo e social que garante a concepção e elaboração de uma política pública comunicativa. As discussões humanas giram sempre em torno de dois propósitos, quais sejam: a realização de fins ou a conquista de entendimento. No primeiro caso, estar-se-á diante do telos que leva ao público como o privado das políticas públicas ou políticas falsamente públicas, ao passo que, no segundo, leva ao público propriamente dito.

A política é pública (1) quando os atores sociais de uma dada situação de fala e ações se encontram representados ou presentes (forma); (2) 
agem comunicativamente para o entendimento, utilizando atos de fala, cuja validez é sempre criticável (função); (3) em seus diferentes momentos, incluindo o início e desenrolar do processo argumentativo consensual (processo); e (4) se estende, quando se passa para a realização da ação, aos momentos de execução, avaliação, controle e decisão (estrutura).

\section{0 papel das políticas públicas mentalistas e o desenvolvimento regional brasileiro}

As politicas públicas mentalistas congregam aquelas de cunho cognitivo-instrumental, desenvolvimentistas e neoliberais. Por políticas públicas e desenvolvimento regional cognitivo-instrumental entendem-se as políticas e o desenvolvimento que foram concebidos e levados a cabo no Brasil com base na razão instrumental e nas ações orientadas para fins, assim como as define Habermas (1990).

Esses tipos de políticas e de desenvolvimento regional dominaram até recentemente o cenário das ações estatais sobre o espaço. Elas ganharam impulso significativo no período 1955-1960, no governo de Juscelino Kubitschek, e atingiram seu auge entre 1964-1985, durante o período militar. A partir do final da década de 1980 essas políticas se arrefeceram.

Do ponto de vista que interessa a este trabalho, as políticas e o planejamento cognitivo-instrumental subdividem-se em duas fases: a primeira, chamada de políticas públicas e desenvolvimento regional desenvolvimentistas, guiadas pelo Estado e normatizadas pelo poder político, e a segunda, chamada de políticas públicas e desenvolvimento regional neoliberais, guiadas pelo mercado e normatizadas pelo dinheiro.

As políticas públicas cognitivo-instrumentais, ou orientadas para fins, devem ser vistas como historicamente situadas. Daí, a necessidade de se levar em consideração as interações entre Estado, Capital e Região inicialmente, no contexto do desenvolvimentismo, e, posteriormente, no contexto do neoliberalismo, já que assumem contornos diferentes em cada um deles.

A década de 1950 pode ser considerada como o momento de elaboração da primeira grande política pública e do primeiro grande programa de desenvolvimento regional do Brasil. Isto ocorreu mediante o planejamento estatal de caráter desenvolvimentista institucionalizado no Plano de Metas e na Sudene. Com a criação desse plano e dessa superintendência foram inaugurados no Brasil, de forma sistemática, as políticas públicas e 
o desenvolvimento regional brasileiro de caráter cognitivo-instrumental, embora, em períodos anteriores, tenha havido programas dessa natureza, ainda que de reduzido alcance. Essas políticas tinham como tripé de sustentação o Estado, o grande capital e as macrorregiões.

Em razão de sua orientação instrumental, a política regional desenvolvimentista brasileira pode ser vista como uma política de crescimento econômico regional, pois sua razão de ser, tendo sido calculista e egocêntrica, privilegiou o mundo do sistema em detrimento do mundo da vida. Como lembra Andrade (1998, p. 111), o planejamento nos países capitalistas se estrutura para oferecer vantagens às empresas, aceitar a racionalidade da acumulação de capital a curto prazo e não dar contribuição de monta à solução dos problemas sociais ou ambientais.

É pertinente perceber a política de desenvolvimento regional desenvolvimentista como de crescimento das economias regionais, pois, conforme esclarece Brum (1998, p. 232), o desenvolvimentismo brasileiro define-se como

um modelo de desenvolvimento voltado centralmente para a realização de um crescimento econômico acelerado, em ritmo superior aos padrões históricos tradicionais, com o objetivo de diminuir a distância de nível de industrialização e renda em relação aos países considerados desenvolvidos.

De acordo com Cidade et al. (2006, p. 25), "o planejamento centralizador, instrumento técnico de suporte à ação governamental intervencionista era guiado por princípios de racionalidade técnico-burocrática no Estado fordista”. Portanto, durante todo o período desenvolvimentista e desenvolvimentista-ditatorial, a sua forma de ação foi a cognitivo-instrumental, guiada pelo êxito com base na relação entre a escolha de meios adequados e a realização de fins. Esses autores revelam ainda que, durante o período aqui delimitado como o de predomínio das políticas públicas instrumentais, não há registro de participação de entidades civis diretamente na discussão dos planos de desenvolvimento, seja no período Kubitschek, seja no período militar. Para Brum (1998, p. 238), com a administração paralela, ampliou-se o poder do Executivo frente ao Legislativo, e, consequentemente, sobre os processos de entendimento, resultando em acentuação do papel do Estado frente ao desenvolvimento e sua predominância sobre a sociedade civil. 
Por outro lado, a própria adoção da macrorregião como escala de intervenção privilegiada das políticas públicas desenvolvimentistas era um dado problemático para a participação da sociedade nas discussões sobre as questões regionais. Para Bandeira (2004, p. 5-6), ao não participar dos processos de concepção, implementação e avaliação dos projetos e programas, a comunidade tendia a não se identificar com eles, o que reduzia sua sustentação política e aumentava a possibilidade de sua efemeridade.

Para Cidade et al. (2006, p. 28), "a expansão territorial e a maior integração regional, embora tenham significado melhoria na infraestrutura econômica nacional não se refletiram em melhoria na precária infraestrutura social do país, permanecendo, em grande medida, as grandes disparidades regionais”. Como assinala Ruiz (2004, p. 11), a opção por sistemas de transportes inter-regionais pode contribuir para acelerar a taxa de crescimento da economia, mas amplia as desigualdades regionais, posto que as regiões são desiguais.

O enfoque macrorregional das políticas públicas de desenvolvimento regional pelo Estado brasileiro inevitavelmente requeria ações de cunho inter-regional, em razão da falta de integração do território nacional. Conseguida a integração, outras escalas menos abrangentes passam agora a ser valorizadas por causa do processo de ajustamento ao novo paradigma dominante na área, que enfatiza a dinâmica interna das regiões, incluindo questões políticas e sociais (Bandeira, 2004, p. 3). Assim, uma nova configuração entre o Estado, o Capital e a Região se estabelece ao final desse período. O Estado e as macrorregióes se enfraquecem nas políticas de desenvolvimento regional e novas escalas passam a ser privilegiadas por elas e pelas empresas.

O neoliberalismo adotado no Brasil a partir da década de 1990 impôs ao país, celeremente, suas normas internas, apresentando-se, hoje, como um repertório vocabular amplamente mencionado não apenas pelos agentes hegemônicos da economia, como também por aqueles que habitam o mundo da vida compartilhado intersubjetivamente.

Assim, a competitividade é uma palavra de ordem, de tal modo que o papel das políticas públicas neoliberais para o desenvolvimento regional consiste em espacializá-la regionalmente. Em lugar de a competição estabelecer-se entre as empresas, são as regiões que passam a competir entre si em busca de vantagens não mais naturais, mas fabricadas. Veja-se que, entre as estratégias da PNDR (Brasil, 2007), a competitividade 
econômica e a produtividade aparecem ao lado da inclusão social e da sustentabilidade ambiental.

Por outro lado, essa competitividade é acompanhada, pelo lado político, da diminuição dos Estados e da consequente descentralização política. "Pode-se mesmo dizer que é crescente a percepção da inconciabilidade entre o objetivo de tornar-se competitivo e a manutenção de estruturas decisórias centralizadas" (Boisier, 1996, p. 112). Com a crise da relação entre Estado e capital, marca do desenvolvimentismo, e com a passagem do fordismo para a produção flexível (Harvey, 2003) e o advento do neoliberalismo, os governos buscam agora uma aproximação com a sociedade como forma de obter legitimação política para suas ações e intervenções.

Nesse período neoliberal, é papel das políticas públicas implementar um programa de desenvolvimento regional que garanta a abertura externa das regiões em razão de suas potencialidades. Conforme Boisier (1996, p. 114), essa abertura objetiva enquadrar as exportações nacionais em dois espaços do comércio internacional. No espaço da modernidade, trata-se de vender produtos e serviços com elevado valor agregado; no espaço da competitividade, agir em benefício da capacidade de aumentar a participação em segmentos produtivos ou de serviços em expansão.

A mesorregião e a escala local passam a ser privilegiadas nas políticas de desenvolvimento regional, abrindo-se a possibilidade para a participação direta da sociedade. Assim, o viés comunicativo das políticas públicas emerge no interior do processo de redemocratização e do neoliberalismo brasileiro.

Bandeira (2004, p. 3) relaciona a referência à escala mesorregional e as ações voltadas para a articulação e empowerment dos atores sociais locais com a capacidade de mobilização do seu potencial endógeno. Na medida em que a endogenia substitui o conteúdo exógeno, logo instrumental, das políticas públicas de desenvolvimento regional, abre-se a condição para a emergência do paradigma comunicativo nessas políticas.

Todavia, como advertem Brandão, Costa e Silva (2004, p. 9), "nenhuma escala per si é boa ou é ruim. É preciso discutir a espacialidade dos problemas e implantar políticas levando em consideração a escala especifica destes, mas em um contexto em que esteja presente um projeto nacional de desenvolvimento", razão pela qual as demais escalas devem ser levadas em consideração pelas políticas públicas, não caindo, assim, numa concepção localista do desenvolvimento regional. 
0 papel das políticas públicas e 0 desenvolvimento regional comunicativo brasileiro

Qual seria, então, numa perspectiva comunicativa, o papel das políticas públicas no que se refere ao desenvolvimento regional? O que se entende por políticas públicas nessa perspectiva? Da mesma forma, o que se entende, com base nela, por desenvolvimento regional?

É papel das políticas públicas comunicativas a concepção correspondente de um desenvolvimento regional contraposto às políticas públicas e ao desenvolvimento regional instrumental. Neste contexto, é essencial a promoção dos espaços públicos de discussão, na medida em que as novas abordagens das políticas públicas brasileiras, contrapondo-se às desenvolvimentistas, favorecem as ações que são concebidas "de baixo para cima” e que levam em consideração os múltiplos atores regionais (Bandeira, 2004, p. 4).

Uma política pública de desenvolvimento regional deve ter como papel a definição daquilo que, a partir dela, deve ser implementado espacialmente. O desenvolvimento regional instrumental desenvolvimentista pautou-se na construção de macrossistemas técnicos (Santos, 1998), e, portanto, no sistema de objetos nacionais e regionais, bem como na opção pelo sistema de ações orientadas para o êxito dentro das empresas e instituições estatais.

Numa perspectiva comunicativa, é papel precípuo das políticas públicas de desenvolvimento regional a criação de espaços permanentes de discussão pública, através dos quais os segmentos do mundo da vida regionais socialmente organizados possam falar e ouvir sobre algo em seus mundos objetivo, social e subjetivo, que venham a fazer parte das políticas de desenvolvimento regional.

Ainda aqui cabe admitir para as políticas públicas um papel na abertura interna, cujo objetivo é incluir a população na dupla condição de igualdade e participação. "Em outras palavras, trata-se de distribuir os lucros derivados exatamente da abertura externa de um modo mais equitativo do que ocorreu no passado, e de outorgar à população um papel mais destacado na definição de opções políticas pertinentes a cada escala territorial” (Boisier, 1996, p. 118).

Neste particular, as políticas públicas e o planejamento comunicativo subordinam os objetivos das políticas públicas e dos planejamentos cognitivo-instrumental e neoliberal aos seus. O modelo econômico 
subordina-se, dessa forma, ao modelo cívico-territorial, ao exigir que "devemos partir do cidadão para a economia e não da economia para o cidadão" (Santos, 2000, p. 5), quando falamos no papel de políticas públicas comunicativas.

A comunicação ou ação orientada para o entendimento mútuo livre de coação como dado constitutivo da política pública comunicativa é um dos meios através dos quais o "projeto político regional" (Boisier, 1996, p. 124), como "instrumento de criação de poder político", pode se realizar.

Este projeto, no dizer de Boisier (p. 124), se realiza pela

“criação de poder político" por meio da cultura da cooperação, do consenso político e do pacto social, enfim, por intermédio do paradigma linguístico, cujas comunidades de fala se orientam nos mundos objetivo, social e subjetivo em torno do entendimento mútuo. Por outro lado, enquanto "transferência de poder político", resulta de um "projeto nacional descentralizador.

Central nas políticas públicas comunicativas é a discussão social na busca de entendimento em torno de questões de desenvolvimento regional que sejam de interesse nacional, como as ligadas ao meio ambiente, particularmente porque, "quanto às preocupações ambientais, estas eram inexistentes no âmbito das políticas públicas e dos empreendimentos privados" (Cidade et al. 2006, p. 27) durante o período desenvolvimentista ou cognitivo-instrumental.

\section{Conclusão}

O desenvolvimento regional, aquele que subordina o modelo econômico ao modelo cívico-territorial a ser buscado pelo Estado e pela sociedade brasileiros, deve levar em consideração, essencialmente, uma política pública comunicativa, entendida como aquela que adota a razão e as ações comunicativas como norma de sua concepção, elaboração, implementação e avaliação.

Estas políticas e este desenvolvimento comunicativos devem obedecer às normas da forma, função, processos e estrutura pública da discussão ou diálogo social em torno das questões dos mundos objetivo, social e subjetivo dos falantes e ouvintes que partilham um mundo da vida comum e que se relacionam a um mundo sistêmico particular dentro da totalidade em constante totalização. 


\section{Referências}

ANDRADE, M. C. Geografia econômica. 12. ed. São Paulo: Atlas, 1998.

BANDEIRA, P. S. As mesorregiões no contexto da nova política federal de desenvolvimento regional: considerações sobre aspectos institucionais e organizacionais. Belo Horizonte: Cedeplar, 2004.

BOISIER, S. Em busca do esquivo desenvolvimento regional: entre a caixa-preta e o projeto político. Planejamento e Políticas Públicas, n. 13, p. 111-143, jun. 1996. Disponível em: < http://www.ipea.gov.br/pub/ppp/ppp13/boisier.pdf>. Acesso em: 24 ago. 2007.

BRANDÃO, C. A.; COSTA, E. J. M.; SILVA, M. A. Construir o espaço supra-local de articulação socioprodutiva e das estratégias de desenvolvimento. Belo Horizonte: Cedeplar, 2004. Disponível em: <https://www.cedeplar.ufmg.br/>. Acesso em: 4 jan. 2007.

BRASIL. Senado Federal. Subsecretaria de Informações. Lei n. 10.257, de 10 de julho de 2001. Regulamenta os arts. 182 e 183 da Constituição Federal, estabelece diretrizes gerais da política urbana e dá outras providências. Disponível em: $<$ https://www.planalto.gov.br/>. Acesso em: 15 abr. 2006.

BRASIL. Presidência da República. Casa Civil. Subchefia para Assuntos Jurídicos. Decreto n. 6.047, de 22 de fevereiro de 2007. Institui a Política Nacional de Desenvolvimento Regional - PNDR e dá outras providencias. Disponível em: $<$ https://www.planalto.gov.br/>. Acesso em: 15 ago. 2007.

BRUM, A. J. O desenvolvimento econômico brasileiro. 18. ed. Petrópolis: Vozes, 1998.

CIDADE et. al. Políticas de ordenação do território: a contribuição de experiências nacionais e estrangeiras. Brasília: Ministério da Integração/UnB/CDS/IICA/ ABIPTI, 2006. Disponível em: <http://www.integracao.gov.br/>. Acesso em: 1 jan. 2007.

HABERMAS, J. Pensamento pós-metafísico: estudos filosóficos. Tradução de Flávio Beno Siebeneichler. Rio de Janeiro: Tempo Brasileiro, 1990.

HABERMAS, J. Teoría de la acción comunicativa: racionalidad de la acción y racionalización social. 4. ed. Madrid: Taurus, 2003. v. I.

HARVEY, D. Condição pós-moderna. Tradução de Adail Ubirajara Sobral, Maria Stela Gonçalves. 13. ed. São Paulo: Edições Loyola, 2003.

RUIZ, R. M. Politicas regionais na nova Geografia Economica. Belo Horizonte: FACE/CEDEPLAR/Ministério da Integração, 2004. Disponível em: <https://www. cedeplar.ufmg.br/>. Acesso em: 4 jan. 2007.

SANTOS, M. Técnica, espaço, tempo: globalização e meio técnico-científico informacional. 4. ed. São Paulo: Hucitec, 1998.

SANTOS, M. O espaço do cidadão. 5. ed. São Paulo: Nobel, 2000. 
Rosalvo Nobre Carneiro - Mestre em geografia pela Universidade Federal de Pernambuco e UFPE e professor assistente II do Departamento de Geografia da UERN/CAMEAM.

Recebido para publicação em julho de 2010

Aceito para publicação em novembro de 2010 